\title{
The Provision of Basic Levels of Computer Literacy and Education to the Neediest Community in South Africa
}

\author{
Ramorola Mmankoko Ziphorah \\ University of South Africa
}

\begin{abstract}
Computer literacy plays an increasingly important role to people's lives and to socioeconomic development. Computer is a technology that has emerged, and globally been adopted quickly. It is important that computer literacy and education be part of the curriculum for children in all parts of the world, in order to bridge the digital divide. Unfortunately, many South Africans, especially in disadvantaged communities and townships have never interacted with a computer before and the majority of children are growing up in a computer illiterate environment. This paper reports on the results of a case study conducted in an urban township of South Africa. The study investigates the teaching and learning strategies that children aged between eight and thirteen years used to acquire basic levels of computer literacy and education in a minimal way. I outlined the teaching and learning strategies in South Africa with relation to the Indian minimally invasive education. I report the results of a qualitative study, in which some of my participants were computer illiterate. My results support the view that a computer can provide equal opportunity and required context to children from all types of socioeconomic and cultural background to achieve basic levels of literacy and education.
\end{abstract}

Keywords: Computer literacy, computer, information and communication technology, Internet, digital divide, minimally invasive education, digital doorway project, teaching and learning strategies, self discovery, peer learning.

\section{Introduction}

Information and communication technologies (ICTs) have grown increasingly, universally, powerfully and adaptable. They change the world we live in and how we learn to live. The young generation is therefore, entering a changing technology-oriented and knowledge-based global economy and society in which national economics are becoming more globalised, with an increasing flow of information, technologies, products, capital and people between nations. A computer as one of the ICTs has emerged

and globally been adopted quickly. Therefore, computer literacy need no longer be a privilege of people who are educated and can moreover, afford to access computer at home or at their work place [3]. Knowing how to use a computer, especially a personal computer, is a basic skill necessary to succeed in business and function effectively in society. Children who do not have access to computers either in the home or at school will develop "information poverty" [4]. It has recently become of vital importance to formulate new and bold solutions to overcome the technological problem; computer illiteracy for the majority of disadvantaged children.

In this study I wanted to investigate the teaching and learning strategies used by children to teach themselves the basic levels of computer literacy skills. Instead of a wide survey I outline a deep qualitative insight in the computer literacy skills in South Africa. Firstly, I examined the rate at which the computer was used. This helped me to investigate whether or not children acquired computer literacy skills through the launch of the Digital Doorway project. Secondly I explored the techniques used to achieve computer literacy skills. It is necessary to assess how computers, as a pedagogic mechanism can help provide equal opportunity and required context to children from all types of socioeconomic and cultural background to learn and achieve basic levels of literacy and education. Thirdly, I identified the value of the social interaction between users. Computer literacy can be very rewarding for people of all ages: children, teenagers, adults and senior citizens [5].

\section{Computer Literacy}

According to a dictionary printed nearly two decades ago [20] literacy is solely defined as "the ability to read and write." A more recent dictionary [18] additionally defines literacy as "The condition or quality of being knowledgeable in a particular subject or field." based on these definitions, the concept "computer literacy" will be defined as knowledge and understanding of computers and their uses [17]. To access the skill levels of users, a computer literate person should be able to perform the following: turn a personal computer (PC) on; use Microsoft Paint to create a designated picture; move objects using folders, shortcuts, cut-and-paste, drag and drop, copy and delete texts; move from one web page to another and back; send and receive e-mail 
through a PC that is pre-configured to do so [12; 5]. It is however, not a prerequisite for a computer literate person to be a good programmer or an expert in computer communications and networking, nor does one need a college degree in computer field to be computer literate [9]. A computer literate person can use the computer technology to perform his job more effectively and efficiently.

Some of the benefits of computers are described as follows [5]:

i. The internet enables us to find a wealth of information on a variety of topics, such as health, cooking, nutrition, entertainment, weather report, road maps and directions, etc.

ii. The online shops on the Internet can be used to purchase items and get them delivered to your house without having to leave the comfort of your house and without having to fight the traffic or bad weather. Today, the utility bills and other bills can be paid online, and banking transactions can be made online which saves time and postage.

iii. With the spread of global Internet connectivity, email has become very popular way to communicate electronically without having to handwrite or type the documents, stuff it in an envelope, seal and stamp it, and then drive to the post office to mail it. This manual process of communication becomes even more cumbersome and costly if you have to mail the same document to multiple people. One can compose and send an email anywhere in the world at any hour of the day or night from the comfort of one's home. For senior citizens, this is a very easy, inexpensive and satisfying way to keep in touch with children and grandchildren. Playing games on the computer, surfing the Net, and sending or receiving email alleviates boredom and solitariness

iv. Internet is available $24 / 7$ and can be a great tool to search for a job. The local Chamber of Commerce, local companies, local colleges and universities post job opening on their Web sites.

We live in a computer-centric information age. For many centuries, pen, pencil, paper, and printed books have been the primary mode of writing, reading, and learning. That mode of writing, reading and learning is changing in today's computer-centric society. It is however challenging to the majority of people to acquire some basic levels of computer literacy skills due to lack of good schools which are also expensive to be afforded by all. These schools are also difficult to be build in remote areas. Additionally, good teachers of computers and information technology are unlikely to exist or move to rural and other remote areas, they are rare and expensive, at the same time computers are, and will continue to be more functional, cheaper and faster [13]. Children in environments that do not promote the use of computers can promote inequalities with cumulative effects over time, further marginalizing the same children who are also often disadvantaged by socioeconomic status and other risk factors related to reading and writing literacy [15]. To foster the spread of computer literacy worldwide, the global digital divide needs to be bridged.

\subsection{Digital Divides in South Africa}

Digital divide is the term that means that not everyone in the world has the same access to information and communication technology [5]. Digital divide can be described as "some people have the most powerful computers, the best telephone services and fastest Internet service, as well as wealth of content and training relevant to their lives, whereas other group of people do not have access to the newest and best computers, the most reliable telephone service or the fastest or most convenient Internet services. A good example is that of people in affluent societies, such as the United States of America and Europe who have the faster and better access to Internet and other information and telecommunication technologies than people in poor and developing countries. It is from this notion that the digital divide is also described as the differing imbalances that exist between countries that are in the fortunate position to reap the advantage of the information age and those countries that are not in the same position [16]. The digital divide does not only exist between developed and developing countries in the world, but also observed between those countries who have access to technology and those who do not have access to technology within the borders of a country, and among other things, in gender, physical disability, race and age. It is well known in most countries that people in rural areas do not have as good access to information technology as those living in suburban and urban areas, those people with inferior quality and less access to information technologies are at a disadvantaged area of the e-commerce because they cannot reap the benefits of the e-commerce [5]. The challenge of digital divide also prevails in South Africa as a developing country. However, the pattern might be different from developed countries.

South Africa is mostly affected by the digital divide in relation to ICT resources. There is a lack of infrastructure for ICT which widens the gap between Africa and the developing world. This knowledge gap exists between the resource-advantaged learners and the resource-deprived learners. To bridge the challenge of digital divide in South Africa, the Council for Scientific and Industrial Research 
(CSIR) in collaboration with the Department of Science and Technology (DST), launched the Digital Doorway Projects throughout South Africa to provide people with access to information. The Digital Doorway has the potential to be a key player in the introduction of computer literacy into the South African environment

\subsection{Background to the Digital Doorway Project}

The Digital Doorway Project commenced in 2002 and sought to bring computer technology within reach of disadvantaged communities in South Africa. The first South African Digital Doorway unit was installed in the rural and remote village in November 2002, and the second installation was launched in the urban township on the $30^{\text {th }}$ of June 2004. The primary aim of this project is to allow users within walking distance of the device to teach themselves basic computer literacy skills through experimentation and peer learning, without intervention of an official teacher or instructor [6]. The Digital Doorway project set out to confirm that children and adults could teach themselves how to master basic computer skills, merely by having free access to a computer and being allowed to explore and try out things on their own [7]. The Digital Doorway terminals are designed to be social entities where a number of users congregate in one place and participate both in peer learning as well as individual interaction with the system [6].

The first installation supports a server and user PC, both running predominantly proprietary software. The server is running MS Windows 2000 operating system and the user PC is running Windows XP operating system. A number of the applications on the system are commercial products, hence a keyboard and touch pad were employed rather than a touch screen [7]. The content includes educational applications and games, paint programs, email and Internet access, Open Office and PDF documents on relevant information such as HIV/AIDS awareness. Based on the learning gained from the first installation, significant changes were made to the design of the second installation. The project team decided to move from a Windows platform to an open source platform due to number of reasons. The changes are classified in Table 1.

The CSIR and the DST has realized the importance of computer literacy as of paramount importance to development in today's world, and also regard the Digital Doorway Project as one of the best, cheapest and most innovative methods of meeting the technological needs of developing countries. The central idea of the Digital Doorway Project is to provide people in rural and disadvantaged areas with computer equipment and allow them to experiment and learn with minimal external input [7]. This learning approach is results from the concept of minimally invasive education (MIE) and seeks to test if children even poor ones can manage to teach themselves basic computer literacy skills without the guidance of an adult.

In both installations there is neither evidence of formal teaching nor an indication whereby an adult guided these children towards acquiring basic computer skills. The methods children used to learn and acquire basic computer literacy skills are not well known. It is therefore important to address the following question:

What are the teaching and learning strategies used by children to acquire the basic computer literacy skills?

\subsection{Earlier Research on the Basic Levels of Computer Literacy and Education}

Earlier work often referred to as the "Hole-in-theWall” experiments has shown that groups of children can learn to use public computers on their own [10]. The goal of these India-based experiments, first conducted in 1999, in 23 locations was to determine if children, given unlimited, free access to computers and the Internet, would be capable of learning how to use a computer without or with little assistance or guidance [8]. In doing so, high-speed computers fitted with a mouse and keyboard, connected to the Internet were installed in the hole in the walls to protect them from vandalism [2]. Children were immediately attracted to the machine installed and their interactions at the computer were monitored by a remote computer and a video camera, which was mounted in a tree close to the "Hole-in-the-Wall" kiosk. This learning method was termed "Minimally Invasive Education”.

Minimally invasive education (MIE) is a pedagogic method and derives its name partly from the medical term "minimally invasive surgery." For the purpose of this study, the concept "minimally invasive education" is defined as a pedagogic method that uses the learning environment to generate an adequate level of motivation to induce learning in groups of children, with minimal, or no intervention by a teacher [8]. In MIE, the role of the teacher is limited to providing, or guiding learners to environments that generate adequate levels of interest. A known example of MIE is the type of learning that takes place when an appropriate puzzle is given to children with little or no input from others. The computer itself is capable of generating such intervention from time to time [13]. In the context of MIE, there is a belief that children, even terribly poor ones with little education, can quickly teach themselves the rudiments of computer literacy. In line with this view, the Indian researchers stipulate that the acquisition of basic computing skills by any set of children can be achieved through incidental 
Table 1. Comparing open source and proprietary solutions [7]

\begin{tabular}{|c|c|c|c|}
\hline & Proprietary & Open source & Notes \\
\hline $\begin{array}{l}\text { User PC operating } \\
\text { system }\end{array}$ & Windows XP & Debian Linux & $\begin{array}{l}\text { Significant licensing cost savings is } \\
\text { going open source. } \\
\text { Good remote administration and } \\
\text { monitoring. }\end{array}$ \\
\hline Server operating system & Windows 2000 & FreeBSD & $\begin{array}{l}\text { Better remote management with } \\
\text { FreeBSD. }\end{array}$ \\
\hline $\begin{array}{l}\text { Familiarity (installation } \\
\text { team) }\end{array}$ & High & Medium & $\begin{array}{l}\text { Valuable learning took place in } \\
\text { installing FreeBSD and Linux }\end{array}$ \\
\hline Familiarity (users) & Low & Low & $\begin{array}{l}\text { Users in the urban area display similar } \\
\text { learning patterns to those in the rural } \\
\text { area. }\end{array}$ \\
\hline $\begin{array}{l}\text { Operating system cost } \\
\text { (for user PC+ server) }\end{array}$ & R6000 & R0 & - \\
\hline $\begin{array}{l}\text { Once off } \\
\text { installation/configuration } \\
\text { time }\end{array}$ & Medium & High & $\begin{array}{l}\text { Debian Linux took longer to configure } \\
\text { than XP. This is partly as a result of } \\
\text { Linux’s extreme customizability. }\end{array}$ \\
\hline $\begin{array}{l}\text { Replication time } \\
\text { (identical hardware) }\end{array}$ & Medium & High & $\begin{array}{l}\text { Custom Linux software distributions can } \\
\text { be created to reduce replication time. }\end{array}$ \\
\hline Internet & $\begin{array}{l}\text { Internet } \\
\text { Explorer }\end{array}$ & Mozilla & $\begin{array}{l}\text { Mozilla supports a number of South } \\
\text { African languages. }\end{array}$ \\
\hline e-mail & Web-based & Web-based & \\
\hline Multimedia player & Media Player & XMMS/etc & \\
\hline Office suite & Office 2000 & \begin{tabular}{l} 
Open Office or \} $\\
{\text { Office }}$ & $\begin{array}{l}\text { Large cost savings if Open Office is } \\
\text { used. }\end{array}$ \\
\hline Windows manager & MS Windows & KDE 3.1 & \\
\hline Educational software & $\begin{array}{l}\text { PC } \\
\text { Genius/Learning } \\
\text { Land/ Various } \\
\text { free software off } \\
\text { Internet. }\end{array}$ & $\begin{array}{l}\text { Gcompris, } \\
\text { Kletters, Solar } \\
\text { System, etc. K- } \\
\text { Edu Suite. }\end{array}$ & $\begin{array}{l}\text { Windows educational software was } \\
\text { donated. There is more Windows based } \\
\text { educational content than open source } \\
\text { content at this stage. }\end{array}$ \\
\hline Language support & English & $\begin{array}{l}\text { English, } \\
\text { Afrikaans, Zulu, } \\
\text { Xhosa, Venda }\end{array}$ & $\begin{array}{l}\text { Local languages supported in both } \\
\text { Mozilla and KDE. }\end{array}$ \\
\hline Video capture software & Eagle-DVR & FFMpeg & $\begin{array}{l}\text { Eagle-DVR proved superior in this case. } \\
\text { In both cases the video capture software } \\
\text { was installed on the server. }\end{array}$ \\
\hline Web-cam software & Logitech & QCCam & \\
\hline
\end{tabular}
\end{tabular}


learning provided the learners are given access to a suitable computing facility, with entertaining and motivating content and some minimal (human) guidance [12].

Minimally invasive refers to the least possible, negligible, or the minimum help required by the child to initiate and continue the process of learning basic computing skills. This minimal amount of help from other children at the MIE learning station is necessary and sufficient for the children to become computer literate [13]. This help which is the fundamental aspects of MIE, could be from peers, siblings, friends, or any other child familiar with computers. In this instance, children collaborate and support each other in learning new experiences. The environment is characterized by its absence from adult intervention, openness and flexibility [13]. It is from this point that children operate the computer freely at their convenience, consult and seek help from any other child or other children and they are not dictated to by any structured settings [11].

\section{Methodology}

This research follows the research process which undergoes four main steps: Formulation of a theoretical question, selection of appropriate site and methods, data collection and analysis, and a theoretical analysis and proposition. This research employed qualitative research methods, more specifically, a qualitative case study [1]. The focus of this research was the provision of basic levels of computer literacy and education to the neediest communities in South Africa. Data was collected through semi-structured interviews and supplementary techniques such as the video recordings. These videos were recorded in MPEG format on a computer. I visited the CSIR offices for a period of three days to observe and analyse the nonverbal communication that was recorded for two weeks. Each video covered a period of one hour, stored under a name consisting of the date as well as the time of the recording. The sound on the video was mostly inaudible; therefore, it was difficult for me to link the actions to words.

In order to design the interviews, I examined what the research literature writes about the experiences of children with regard to their interaction and participation in a street Internet kiosk. The interviewees were selected through purposive sampling. A purposive sample makes it possible to obtain deep knowledge about research topic, and it fitted well on the qualitative nature of my research [1]. I aimed at identifying at least ten interviewees, I however found thirteen interviewees who volunteered their participation and were the frequent users of the site. All the interviewees were boys aged between eight and twelve years and reside in the same community (urban township in South
Africa). The interviewees were all learners from different public schools.

During the interviews, the same questions were asked to each interviewee. Probing was done to get rich data that enhanced me to answer my research question. Each interview lasted for approximately forty minutes and the interviews were transcribed to text. After the transcription, data was processed by qualitative analysis. Data was organised into categories, and later patterns and relationships among categories were identified. After the empirical part of the research, at the fourth stage of research, I compared earlier research studies to the findings of this research and evaluated the validity of this research study.

\section{Results}

I first looked at the rate at which the computer was used. The observations show a regular increase in the visitation of the kiosk and the usage of the computer by the community members. Different groups of users, especially children popped in all the time. Recordings of the first week dated 2003-12-06 - 2003-12-12 indicates the following:

As early as $08 \mathrm{HOO}$ three young children were in the kiosk and left after eight minutes. A young boy entered, he had to stand on the stool to see the screen. He did not touch any keys. A few adults and a teenager also walked in watched and left again. Later a teenage boy and girl entered, he pressed keys on the computer while the girl watched. After they had left, five young children entered with the security guard. He showed them some few things while they bunched together around the computer. After a while, two other kids joined them. The child in front of the computer got something to work and they became quite exited. Music started playing, which indicated that they were playing some game.

I continued to investigate the kind of teaching and learning strategies that took place at the Digital Doorway project. I found a number of strategies that can also be found in the literature on the topic, and I considered them to fall naturally into two categories: self discovery and peer learning. According to the interviewees, peer learning assisted them in acquiring the computer literacy skills. This is what one of the interviewees said:

"I looked at how my friends pressed the computer. I then imitate the practice and sometimes I press the computer with them".

The group consisted of the "know how" and the "know not" children, adopting the categorization from the "know how" mostly take a lead and teach the "know not" how to operate the computer. One of 
the children the "know how" was seen in front of the computer pressing some buttons as the group members were observing. This will obviously fall under the category 'self discovery'. This is evident from the recordings dated 2003-12-19:

A child aged about ten stood on the footstool and looked around, under the computer as well as behind the computer. Then he stood up and pressed the keys. Initially he was very unsure of himself, but kept trying. After a while, he stood on the footstool and played a game. He left after about fifteen minutes, but returned a bit later with other people, which mean that he might have wanted to show others his newly acquired knowledge. A bit later three adults entered. The adults worked on the computer while the child watched, standing back. The adults left and another child (child 2) entered, at this stage the child was in front of the computer again. Child 2 was very interested and leaned over the computer while looking. After a while, child 2 went to the left hand side and stood with the child on the stool. A teenage boy entered, but only watched from a distance. Then the spectators left while the child stayed in front, pressing keys. While busy people would come in, looked what he was doing and left again. His friends returned after a while and stood closely by to watch. The music indicated that they were playing a game. They left the kiosk, and then three adults, the child and another child (child 3) entered. One of the adults worked on the computer, the others watched. The child was very close to the screen and very interested. When the adults left, the child remained behind. An older boy entered and the child stood on the footstool. He was obviously the leader because he knew what to do. After a while, the older boy started to press keys.

I finished the investigation by looking at the constituents of the social interaction between the Digital Doorway users. Regarding this question, observations indicated three aspects of the mutual interaction in the usage of a computer: child-child (interaction between children themselves); childteenager (interaction between children and teenagers) and child-adult (interaction between children and adults). The social groups ranged from five to eight members of different age groups. There was respect to each other as all the groups could work harmoniously with one computer. There is no evidence of fights between the groups. When asked about their social interaction, the interviewees explained:

"When you arrive and found other people busy with the computer, we give them chance to complete their work. We wait for them. We also share the computer by working together as a group and we respect each other".
My results suggest that knowledge is a social construct, that is, something that is constructed by people, acquired by people and communicated to people [1]. The findings that emerged from my data also reflect my assumption that people construct meaning not only for purpose of interaction but also to make sense of their own and other realities. The result of my inquiry therefore, validates the constructivist paradigm of learning. The constructive paradigm, as advocated by [14] and [19] stress the notion that whatever gets into the mind has to be constructed by the individual through knowledge discovery [14] with a focus on the process of assimilation and accommodation of knowledge.

This study is therefore, located in the theories of constructivism. Constructivism is fundamental departure in thought about the nature of knowing, hence of learning and thus of teaching. The constructivist perspective describes learning as a change in meaning constructed from experience. Constructivists believe that knowledge and truth are constructed by people and do not exist outside the human mind. They agree that students learn by doing. When students actively participate in the learning process by using critical-thinking skills to analyze a problem, they will create, or construct their own understanding of a topic or problem. Constructivist theory, or constructivism, is based on a type of learning in which the learner forms, or constructs much of what he or she learns or comprehends. Piaget and Vygotskian theories are explored in order to understand the type of learning taking place in the context of minimalism.

Jean Piaget $(1896$ - 1980) perceived that children think very differently from adults. He felt children are active learners and do not need motivation from adults to learn. Piaget believed that children are constructing new knowledge as they move through different cognitive stages or schema, building on what they already know. Furthermore children interpret this knowledge differently as they progress through different stages. Piaget defined four cognitive stages namely: sensory motor, preoperational, operational and formal operational. This study is located within the concrete operational and formal operational stages. In his concrete operational stage which begins about age seven [14] indicates that children begin to think logically, to learn many facts and also to understand other points of view besides their own. In the formal operational stage which begins about age twelve. He posits that children transit from concrete thinking to more abstract; they can formulate a hypothesis and understand cause and effect. Children or adolescents begin to formulate their own beliefs and morals. He therefore, concluded that children assimilate new knowledge as they experience new things and learn new information. Children fit this information or these experiences into their lives to change their 
knowledge base and to make sense of their environment and the world around them (accommodation) [17].

More recently, the social orientations of constructivism commonly linked to Vygotsky emphasized the cultural and social context influencing learning [19]. Vygotsky's brand of constructivism is called social constructivism because he emphasized the critical importance of interaction with people - other children in cognitive development. In his social cognition theory he believed that learning is influenced significantly by social development. He further states that every function in the child's cultural development appears twice: first on the social level, meaning between people (interpsychological); and later, on the individual level, meaning inside the child (intrapsychological). Vygotsky therefore theorized that learning takes place within the context of a child's social development and culture. He believed that a child's social environment could positively or negatively affect the child's cognitive development. He then proposed that children have a zone of proximal development, which is the difference between the problem-solving ability that a child has learned and the potential that the child can achieve from collaboration with a more advanced peer or expert. Vygotsky theorized that if a nine year old child worked on a problem with an adult or another child who was advanced, the nine year old would be able to learn the concept or ideas that were more complete than the nine year old could understand on his own (peer learning). Vygotsky felt students should work collaboratively to share their different perspectives with each other; then they could negotiate a solution and come to a much deeper understanding of a problem or tasks [17].

\section{Conclusion}

My research results give an insight in the teaching and learning strategies used by children to acquire the basic computer literacy skills in South Africa. The results support the literature in the sense that I found self discovery and peer learning in the South African context and similar strategies have been proposed in research literature too. In terms of self discovery learning, the most important issue is that children try new things on their own. There is no one to give guidance, no one to ask from and no curriculum provided. The research findings show that the effective implementation of minimally invasive education is the main requirement for the improvement of computer literacy skills at the Digital Doorway Project. This system of education is very useful in the area of learning by doing. Children show a keen interest in the usage of a computer, as it is free and accessible at any time. Therefore, their daily use of computers is increasing both at schools and out of school. Notwithstanding the fact that not all children are computer literate and have access to the computer, the concept of minimally invasive education emerged at the Digital Doorway Project. Children now effectively teach one another basic computer skills, and they are also effective at selfregulating process of learning.

The Digital Doorway Project is found to be of importance to South African citizens. The findings of this project could serve to inform policy makers to introduce alternative mechanisms for computer literacy. It could also suggest another pathway towards building human capacity in support of the advancement of the information society in South Africa and its adjacent regions. The Digital Doorway Project, therefore, set out to confirm that children could teach themselves how to master basic computer skills, merely by having free access to a computer and by being allowed to explore and discover knowledge on their own, that is, without formal training. It is obvious that more contextual relevant studies are needed to overcome the local digital divide.

\section{Reference}

[1] Cohen, L., Manion, L. and Morrison, K. 2000. Research methods in education. Londong:Rutledge and Falmer.

[2] Dangwal, R., Jha, S. and Kapur, P. 2005. "Impact of Minimally Invasive Education on Children: An Indian Perspectives." British Journal of Education Technology 37(2): 295.

[3] Dix, S. 2003. Looking beyond the statistics: the Internet in the Lives of the Emerging Black Market. A Research Paper presented to the SAMRA 2003 conference. http://www.webcheck.Archive.htm

[4] Facer, K., \&Furlong, R. 2001. Beyond the myth of the "cyberkid": Young people at the margins of the information revolution. Journal of Youth Studies, 4(4), 451-469.

[5] Gupta, G.K., (2006). Computer Literacy: Essential in Today's Computer-Centric World. Inroads - The SIGCSE Bulletin, volume 38, Number 2, June.

[6] Gush, K., (2008). Towards a more personalized user experience and better demographic data on the Digital Doorway public computer terminals. Prato CIRN 2008 Community Information Conference: ICTs for Social Inclusion: what is the Reality? Refereed Paper.

[7] Gush, K., Cambridge, G. and Smith, R. 2004. The Digital Doorway - minimally invasive education in Africa. ICT in Education Conference.

[8] Inamdar, P., (2004). Computer skills development by children using 'hole in the wall' facilities in rural India. 
Australasian Journal of Educational Technology, 20(3), 337-350. http://www.ascilite.org.au/ajet/ajet20/

inamdar.html

[9] McKay, D. Computer Literacy: An Important Skill. About, Inc., 2006. http://careerplanning.about.com/ od/importantskills/a/comp_literacy.htm

[10] Mitra, S. 2000. Minimally Invasive Education for mass computer literacy. Conference on Reseach in Distance and Adult Learning in Asia 2000, Hong Kong.

[11] Mitra, S. 2004. The hole in the wall. Dataquest, 23 September. http://www.dqindia.com/content/ industrymarket/2004/104092301.asp\#inte

[12] Mitra, S. \& Rana, V. (2001). Children and the Internet: experiments with Minimally Invasive Education in India. The British Journal of Educational Technology, 32(2): 221-232.

[13] Mitra, S., Dangwal, R., Chatterjee, s., Jha, S., Bisht, S., \& Kapur, P. (2005). Acquisition of computing literacy on shared public computers: Children and the "hole in the wall”. Australian Journal of Educational Technology, 21(3), 407-426. http://www.ascilite.org.au/ajet/ajet21/ mitra.html

[14] Piaget, J. 1960/1981. The psychology of intelligence, Littlefield, Adams and Co, New Jersey.

[15] Poynton, T.A. (2004). Computer literacy across the lifespan: a review with implications for educators. Computers in Human Behavior 21(2005) 861 - 872.

[16] Ramorola, M. Z. 2010. A study of effective technology integration into teaching and learning: A case study. South Africa: UNISA.

[17] Shelly, G., Cashman, T.J., Gunter, R.E., \& Gunter, G.A. (2010). Teachers Discovering Computers. Integrating Technology and Digital Media in the Classroom. USA: Cengage.

[18] The American Heritage Dictionary of the English Language (200). ( $4^{\text {th }}$ ed.). new York: Houghton Mifflin Company.

[19] Vygotsky, LS. 1978. Mind in society: the development of higher psychological processes, Havard University Press, Cambridge, MA.

[20] Websters Dictionary. (1984). New York: Warner Books. 